Korean Chem. Eng. Res., 51(1), 116-120 (2013)

http://dx.doi.org/10.9713/kcer.2013.51.1.116

\title{
$\mathrm{TiO}_{2}$ 광촉매를 이용한 $\mathrm{CO}$ 제거 공정특성
}

\author{
김진길 · 이상문* · 홍성창* · 이의동** · 강 용 \\ 충남대학교 화학공학과 \\ 305-764 대전광역시 유성구 대학로 99 \\ *경기대학교 환경공학과 \\ 443-760 경기도 수원시 영통구 이의동 산 94-6 \\ **하나검사기술(주) \\ 465-220 경기도 하남시 초이동 337-10 \\ (2012년 7월 10일 접수, 2012년 8월 7일 채택)
}

\section{Characteristics of CO Removal Process Using $\mathrm{TiO}_{2}$ Photocatalyst}

\author{
Jin-Kil Kim, Sang-Moon Lee*, Sung-Chang Hong*, Eui-Dong Lee** and Yong Kang ${ }^{\dagger}$ \\ Department of Chemical Engineering, Chungnam National University, 99 Deahak-ro, Yuseong-gu, Daejeon 305-764, Korea \\ *Department of Environmental Energy Systems Engineering, Kyonggi University, 94 San, Iui-dong, Suwon, Gyeonggi-do 443-760, Korea \\ **HANA I\&E, 337-10, Choi-dong, Hanam, Gyeonggi-do 465-220, Korea \\ (Received 10 July 2012; accepted 7 August 2012)
}

\begin{abstract}
요 약
관상의 광촉매 반응기에서 $\mathrm{Pt}$ 가 담지된 $\mathrm{TiO}_{2}$ 광촉매를 사용한 $\mathrm{CO}$ 전환 반응에 의해 $\mathrm{CO}$ 를 제거하는 광촉매 공정에 대해 고찰하였다. $\mathrm{TiO}_{2}$ 촉매에 $\mathrm{Pt}$ 를 담지하는 방법, $\mathrm{CO}$ 를 포함한 기체흐름속도, 기체흐름에 포함된 $\mathrm{CO}$ 의 농도 그리

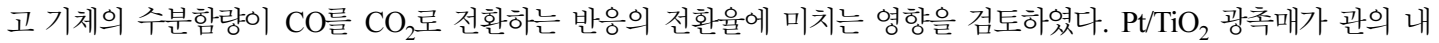
부에 코팅된 관상광촉매 반응기에서 진행된 실험결과 기체의 흐름속도 범위가 $0.01 \sim 0.25 \mathrm{~m} / \mathrm{s}, \mathrm{CO}$ 의 농도가 20 100 ppm 그리고 기체의 상대습도가 $20 \sim 40 \%$ 의 범위에서 $\mathrm{CO}$ 는 UV의 조사 조건에서 거의 $100 \%$ 정도 제거될 수 있었다. 기체 흐름에 포함된 $\mathrm{CO}$ 의 전환율은 기체의 흐름속도가 증가할수록 그리고 포함된 $\mathrm{CO}$ 의 농도가 증가할수록 점점 감소하였 다. 기체 흐름에 포함된 수분은 $\mathrm{OH}$ 라디칼을 형성함으로써 $\mathrm{CO}$ 의 제거를 촉진할 수 있었다.
\end{abstract}

\begin{abstract}
Characteristics of photocatalytic $\mathrm{CO}$ removal process conducting $\mathrm{CO}$ conversion by using $\mathrm{Pt}$ loaded $\mathrm{TiO}_{2}$ photocatalyst were investigated in a photocatalytic tubular reactor. Effects of $\mathrm{Pt}$ loading method onto $\mathrm{TiO}_{2}$, linear velocity of gas stream containing $\mathrm{CO}$ gas, $\mathrm{CO}$ concentration and moisture content in the gas stream on the conversion of $\mathrm{CO}$ to $\mathrm{CO}_{2}$ were examined. It was found that the $\mathrm{CO}$ gas could be removed almost $100 \%$ by using photocatalytic tubular reactor internally coated with $\mathrm{Pt} / \mathrm{TiO}_{2}$ photocatalyst under $\mathrm{UV}$ irradiation, when the linear velocity of gas stream was in the range of $0.01 \sim 0.25 \mathrm{~m} / \mathrm{s}$ and $\mathrm{CO}$ concentration in the gas stream was ranged from 20 to $100 \mathrm{ppm}$ and the relative humidity of the gas stream was in the range of $20 \sim 40 \%$. The conversion of CO gas decreased gradually with increasing linear velocity of gas stream and $\mathrm{CO}$ concentration in the gas stream. The moisture in the gas stream could promote the removal of $\mathrm{CO}$ gas by means of the generation of OHradicals.
\end{abstract}

Key words: CO Removal, Tubular Photocatlytic Reactor, $\mathrm{Pt} / \mathrm{TiO}_{2}$ Photocatalyst, UV Irradation

\section{1. 서 론}

산업발달과 경제발전으로 생활수준이 향상됨에 따라 대기오염이 심화되어 제어해야 할 오염물질이 늘어나고 있으며, 이러한 대기오 염 문제는 날로 심각해지고 있다. 또한, 국민들의 환경에 대한 인식 이 향상됨에 따라 실내공기질에 대한 관심이 높아지고 있다. 실내

\footnotetext{
${ }^{\dagger}$ To whom correspondence should be addressed.

E-mail: kangyong@cnu.ac.kr

*이 논문은 KAIST 박선원 교수님의 정년을 기념하여 투고되었습니다.
}

오염물질은 실외와는 달리 실내의 오염원 또는 외부 오염물질의 유 입에 의해 오염될 경우 정화가 쉽지 않아 하루 중 $90 \%$ 이상을 실 내에서 생활하고 있는 인간에게 단기적으로나 장기적으로 인체에 유해한 영향을 끼치고 있다. 이러한 실내 오염물질을 제어하는 방 법으로는 크게 다섯 가지 방법이 있을 수 있다. 첫째로, 원인물질의 제거 또는 교체방식을 들 수 있는데 이 방법은 오염물질의 근본적 제거라는 장점이 있지만 현실적으로 실행하기 어려운 점들이 단점 으로 지적되고 있다. 둘째로, 환기를 하는 방법은 오염물질을 제거 하는 것이 아니라 단순히 희석시키는 처리법이다. 셋째로, 베이크 
아웃방법인데 이 방법 역시 짧은 시간동안 온도를 증가시켜 흡착되 어 있던 휘발성 유기화합물질을 탈착시켜 환기하는 방법이므로 단 순한 환기일 뿐 오염물질을 근본적으로 제거하지 못하는 단점이 있 다. 넷째로, 공기 정화설비를 설치하는 방법인데 이는 가장 널리 사 용되는 방법 중 하나로 흡착제를 사용하고 있다. 이 방법은 흡착제 를 사용하기 때문에 흡착량이 한정되어 흡착제의 잦은 교체가 필요 하다는 단점이 있다. 다섯째로, 백금 및 전이금속 담지형 촉매를 이 용한 저온산화형 촉매 기술이 있지만 촉매의 비활성화 및 저효율의 문제를 벗어나지 못하고 있다[1-7].

상기 언급한 방법들의 단점을 보완하기 위해서는 우수한 제거효 율과 경제성을 가지며, 수명이 길고 기존의 구조물에 쉽게 부착시 킬 수 있으며 이차적인 환경오염을 일으키지 않는 방법을 사용해야 한다. 이와 같은 조건을 가장 잘 충족시킬 수 있는 방법으로 광촉매 가 제시되고 있는데, 이는 상온, 대기중에서 강한 산화력을 가지며, 화학적으로 매우 안정할 뿐만 아니라 경제적인 측면에서도 비교적 저렴하므로 현재까지 많은 기초 연구가 진행되어 왔고 실용화를 위 한 연구도 활발히 진행되고 있다[1,2].

이러한 연구의 일환으로 본 연구에서는 UV Lamp를 이용하여 상 온에서 $\mathrm{CO}$ 를 제거하는 광촉매 산화공정의 특성을 고찰하였다. 촉 매를 졸 상태로 반응공정의 벽에 코팅할 때 분산 및 효율 증대를 위 하여 두 가지 방법으로 metal을 광촉매에 담지하였으며, $\mathrm{CO}$ 가스 의 농도 및 수분 등이 $\mathrm{CO}$ 의 산화공정에 미치는 영향을 검토하였다.

\section{2. 실 험}

본 연구에서 사용한 촉매는 기존에 상용화되어 있는 국외 2 개의 광촉매 제조사의 광촉매 중 졸 형태의 $\mathrm{TiO}_{2} 3$ 종을 선정하여 전처리 없이 사용하였다. 광촉매 반응기는 촉매를 관상반응기의 벽면에 코 팅하였으며, 이들 촉매를 활성화하기 위해 조사된는 광에너지는 관 상반응기의 중앙에 UV 램프를 설치하여 제공하였다. 반응관 내부 에 $\mathrm{TiO}_{2}$ 광촉매를 Coating하기 위하여 Binder를 사용하였다. Binder 의 제조는 IPA (Isopropyl alchol, Samchun Co., Ltd.), TEOS (Tetraethyl orthosilicate, $98 \%$, Acros organic Co.), DMDMS (Dimethoxydimethylsilane, $95 \%$, Aldrich Co.)를 일정비율 혼합한 용액에 IPA, DI water, 질산 등의 혼합액을 점적하면서 2시간 동안 일정속도로 교반하여 제조하였다. 교반중의 휘발을 억제하기 위하여 혼합액의 온도는 약 $4{ }^{\circ} \mathrm{C}$ 를 유지하였으며 제조 후 냉장 보관하였다. $\mathrm{Binder}$ 와 $\mathrm{TiO}_{2}$ 의 혼 합은 binder 용액에 졸 형태의 $\mathrm{TiO}_{2}$ 를 점적시켜 제조하였다. 광촉매 반응기의 활성을 증대시키기위해 $\mathrm{TiO}_{2}$ 가 코팅된 반응기에 $\mathrm{Pt}$ 금속을 두 가지 방법으로 담지하였다. 첫 번째는 UV 조사에 의한 metal 담지 방법을 사용하였다. 즉, $400{ }^{\circ} \mathrm{C}$ 에서 2 시간 소성하여 제조된 coating 반응관에 $0.1 \% \mathrm{Pt}$ 용액을 채우고 $\mathrm{UV}$ 를 1 시간 조사하였으며 실온 건조 후 $\mathrm{Pt}$ 를 담지한 반응관을 $300{ }^{\circ} \mathrm{C}$ 에서 3 시간 환원 후 $400{ }^{\circ} \mathrm{C}$ 에 서 2시간 소성하여 이를 $\mathrm{Metal} / \mathrm{TiO}_{2}-\mathrm{M} 1$ 으로 표기하였다. 두 번째 방법은 binder와 혼합하기 전에 증류수에 코팅 용액으로 $\mathrm{TiO}_{2}$ 기준 $0.1 \%$ 양의 Metal $(\mathrm{Pt})$ 용액을 먼저 교반시킨 후 담지를 하였으며, 이를 $\mathrm{Metal} / \mathrm{TiO}_{2}-\mathrm{M} 2$ 으로 표기하였다.

광촉매 반응을 수행하기 위한 공정은 Fig. 1과 같이 가스 주입부 분, 반응기, 가스 분석부분등 세부분으로 구성하였다. 반응기 내의 가스 주입은 MFC (Mass Flow Controller, MJS Co.)를 사용하였으 며, 처리대상가스인 $\mathrm{CO}$ 의 농도는 20 100 ppm의 범위에서 사용하였

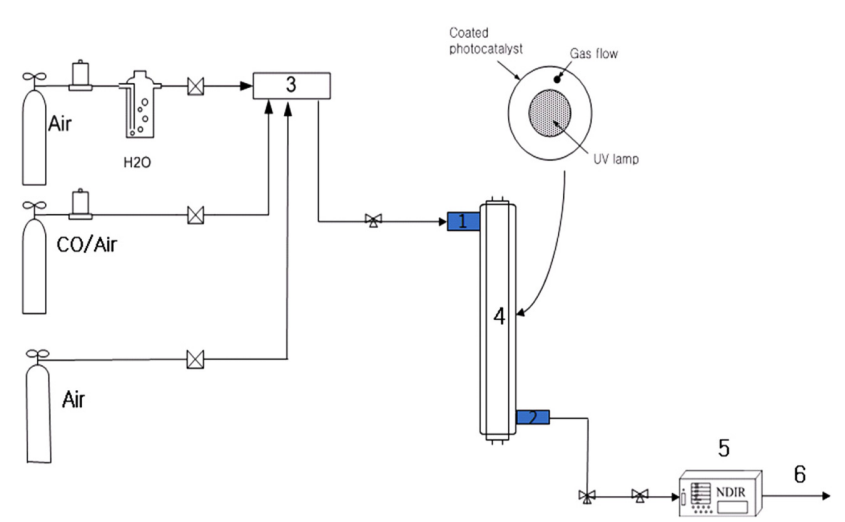

Fig. 1. Schematic diagram of photocatalytic reactor.
1. Inlet
2. Outlet
4. Photocatalyst reactor
3. Mixing
5. $\mathrm{CO}, \mathrm{CO}_{2}$ analyzer
6. Vent

Table 1. Experimental condition in photocatalytic reactor

\begin{tabular}{ll}
\hline \hline Reactor & $\varnothing 50 \times 215(\mathrm{~mm})$ \\
\hline Lamp & $254 \mathrm{~nm}(\varnothing 26, \mathrm{~L}: 380)$ \\
Inlet gas & $10 \sim 100 \mathrm{ppm}$ \\
$\mathrm{RH}(\%)$ & $0 \sim 60 \%$ \\
Linear velocity & $0.0048 \sim 0.079 \mathrm{~m} / \mathrm{s}$ \\
\hline
\end{tabular}

다. 반응공정에 수분의 공급을 위해 공기를 기포발생기(bubbler)를 통하여 수분을 함유한 상태로 반응기에 주입하였으며, 이 때 공급 되는 수분의 양을 일정하게 하기 위하여 기포발생기 외부에 순환기 를 이용하여 일정온도 $\left(20^{\circ} \mathrm{C}\right)$ 를 유지하였다.

반응기로는 외경 $0.05 \mathrm{~m}$, 길이 $0.215 \mathrm{~m}$ 의 Pyrex 관 내벽에 $\mathrm{TiO}_{2}$ 광촉매가 코팅된 반응관을 사용하였다. 광촉매 반응에 사용된 Lamp는 $254 \mathrm{~nm}$ 를 주파장으로 발생하는 TUV10W/G10T8(Philips, 이하 UV Lamp)를 사용하였으며 실험 조건은 Table 1에 나타내었다. 반응물과 생성물의 농도를 측정하기 위하여 $\mathrm{CO}$ 와 $\mathrm{CO}_{2}$ 농도를 측정하였는데, 이들의 농도는 비분산 적외선 가스분석기(ZKJ-2, Fuji Electric Co.) 를 사용하였다. 분석되는 기체는 기체 분석기로 유입되기 전에 수 분을 chiller 내의 수분 trap에서 제거시킨 후 유입하였다. 반응기에 유입되는 기체의 초기농도를 측정하기 위하여 공관에 희석가스(Air) 와 $\mathrm{CO}$ 가스를 주입하여 정상상태에서 농도를 측정하였고, 습도계 (Center310, G-won Hitech Co.)로 상대습도를 측정하였다.

\section{3. 결과 및 고찰}

$\mathrm{TiO}_{2}$ 는 전자를 방출하는 $\mathrm{n}$ 형 반도체이므로, 약 $3.02 ~ 3.2 \mathrm{eV}$ 의 Band gap energy를 갖는 Anatase 결정구조의 $\mathrm{TiO}_{2}$ 는 광에너지를 받 으면 활성화되어 광촉매 반응을 일으킬 수 있다[8-12]. $\mathrm{TiO}_{2}$ 광촉매 의 Band gap energy보다 큰 광에너지를 주기위해 본 연구에서는 근 자외선 영역의 파장을 이용하였다. $\mathrm{TiO}_{2}$ 는 화학적, 물리적으로 안 정하나 광활성화되면 반응성이 커지게 되므로 광활성화에 영항을 미치는 인자에 대한 고찰은 $\mathrm{TiO}_{2}$ 의 광활성을 이용한 공정의 개발에 중요한 의미가 있다 하겠다. $\mathrm{TiO}_{2}$ 광촉매의 활성에 영향을 미치는 주요인자들로는 $\mathrm{TiO}_{2}$ 의 구조, 표면적, 결함 및 수산기 등을 들 수 있는데[3-5] 본 연구에서는 이들 인자들을 세 가지의 $\mathrm{TiO}_{2}$ 광촉매를 대상으로 고찰하였다. 
Table 2. The comparison of each photocatalyst

\begin{tabular}{|c|c|c|c|c|c|}
\hline Manufacturer & Code & BET $\left(\mathrm{m}^{2} / \mathrm{g}\right)$ & Ti Contents $(\%)$ & "Ti contents in coating solution (\%) & Remarks \\
\hline Ishihara sangyo kaisha Ltd. & STS-01 & 104.04 & 30 & 12 & BET:300 m²/g (@Sol. condition) \\
\hline \multirow{2}{*}{ Versa-Tech } & Versa-Tech(I) & 114.08 & 6 & 5 & - \\
\hline & Versa-Tech(II) & 170.72 & 16 & 13.33 & - \\
\hline
\end{tabular}

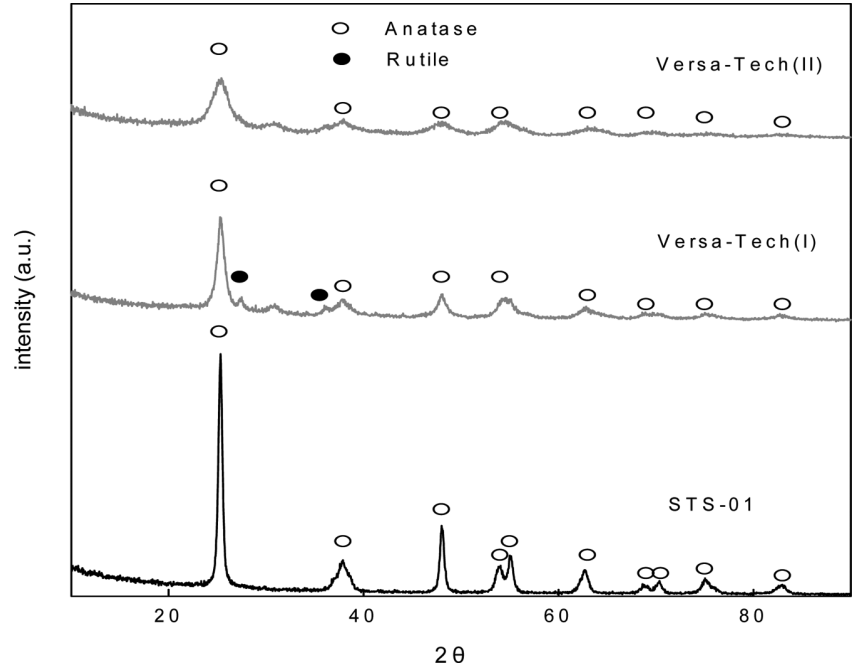

Fig. 2. X-ray diffraction patten of each $\mathrm{TiO}_{2}$.

본 연구에 사용된 세 가지 $\mathrm{TiO}_{2}$ 광촉매의 물리적 특성을 Tablel 2에 나타내었다. Table 2에서 볼 수 있듯이 STS-01 시료의 $\mathrm{TiO}_{2}$ 는 비표 면적이 $104 \mathrm{~m}^{2} / \mathrm{g}$ 이며, Sol 상태의 비표면적은 $300 \mathrm{~m}^{2} / \mathrm{g}$ 을 가졌고, $\mathrm{Ti}$ 함량은 3 개 시료중 $30 \%$ 로 가장 많이 포함하고 있으며, coating solution의 $\mathrm{Ti}$ 함량은 $\mathrm{ICP}$ 분석 결과 $12 \%$ 로 나타났다. 다른 2 개의 시료인 Versa-Tech(I)과 (II) $\mathrm{TiO}_{2}$ 시료의 BET 면적은 각각 114와 $170 \mathrm{~m}^{2} / \mathrm{g}$ 을 이었으며, Ti함량은 6과 $16 \%$ 로 STS-01보다 상대적으로 낮은 값을 나타내었다. 이들 세가지 종류의 $\mathrm{TiO}_{2}$ 광촉매를 $\mathrm{XRD}$ 분석을 하 여 Fig. 2에 나타내었다. Fig. 2에서 볼 수 있듯이 광촉매 시료 STS01와 Versa-Tech(II)는 모두 아나타제(Anatase)로 구성되어 있으나 Versa-Tech(I)은 Rutile 성분을 일부 포함하고 있는 것으로 나타났다.

광촉매 반응에 의한 $\mathrm{CO}$ 의 제거 특성을 조사하기 위하여 세 가지 $\mathrm{TiO}_{2}$ 광촉매에 대하여 광전환 반응을 수행한 결과를 Fig. 3에 나타내었 다. Fig. 3에서 볼 수 있듯이 STS-01, Versa-Tech(I)과 Versa-Tech(II) 의 3 가지 $\mathrm{TiO}_{2}$ 시료를 각각 사용한 공정에서 $50 \mathrm{ppm}$ 의 $\mathrm{CO}$ 을 주입하 고 상대 습도를 $40 \%$ 로 유지하면서 반응시켰을 경우 $\mathrm{CO}$ 의 $\mathrm{CO}_{2}$ 로 의 전환율은 기체의 선속도에 상관없이 거의 나타나지 않았다. 이 결과로 $\mathrm{TiO}_{2}$ 광촉매만으로는 $\mathrm{CO}$ 를 $\mathrm{CO}_{2}$ 로 전환하기 위한 활성을 가지지 않음을 알 수 있었다.

$\mathrm{TiO}_{2}$ 광촉매의 광활성을 높이기 위해 $\mathrm{Pt}$ 금속을 광촉매의 표면에 담지하여 [6,7] 사용하였다. 광촉매에 $\mathrm{Pt}, \mathrm{Ag}, \mathrm{Pd}$ 과 같은 금속의 첨 가는 전자와 전공쌍의 재결합을 조절할 수 있어서 광활성을 효과적 으로 증가시킬 수 있기 때문이다[13-15]. 따라서 본 연구에서는 $\mathrm{TiO}_{2}$ 광촉매의 효율을 증가시키기 위해 $\mathrm{Pt}, \mathrm{W}$ 그리고 높은 양자 수 율을 얻을 수 있는 $\mathrm{Fe}, \mathrm{Mn}, \mathrm{Ag}$ 등을 $\mathrm{TiO}_{2}$ 광촉매에 담지하였으며 이를 사용하여 $\mathrm{CO}$ 의 산화 실험을 수행한 후 그 결과를 Fig. 4에 나 타내었다.

Fig. 4에서 $\mathrm{TiO}_{2}$ 광촉매에 금속을 담지한 방법은 STS-01 TiO 2 에

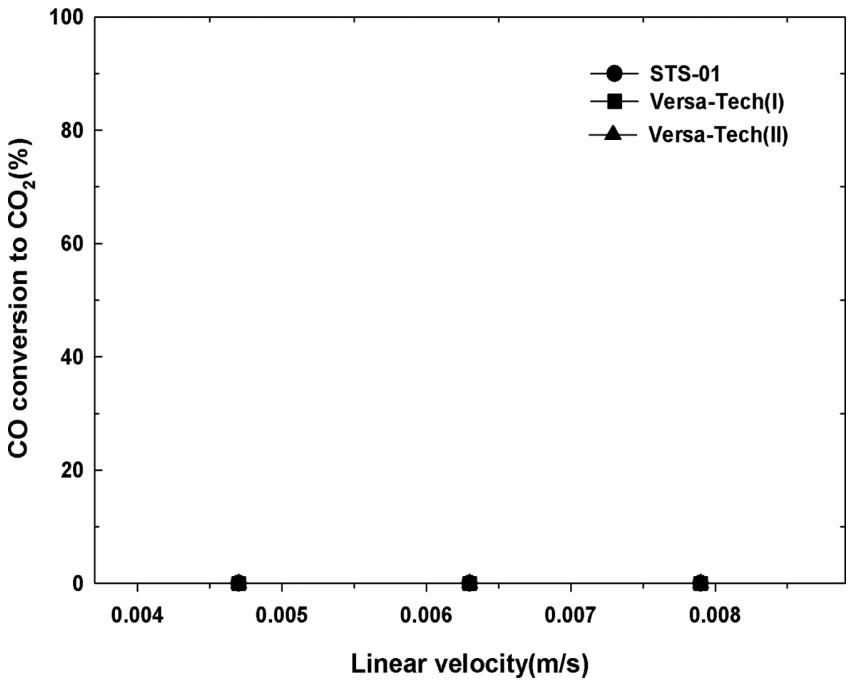

Fig. 3. $\mathrm{CO}$ conversion to $\mathrm{CO}_{2}$ according to each $\mathrm{TiO}_{2}$ (moisture content : $\mathbf{4 0 \%}$, Inlet concentration : CO $50 \mathrm{ppm}$ ).

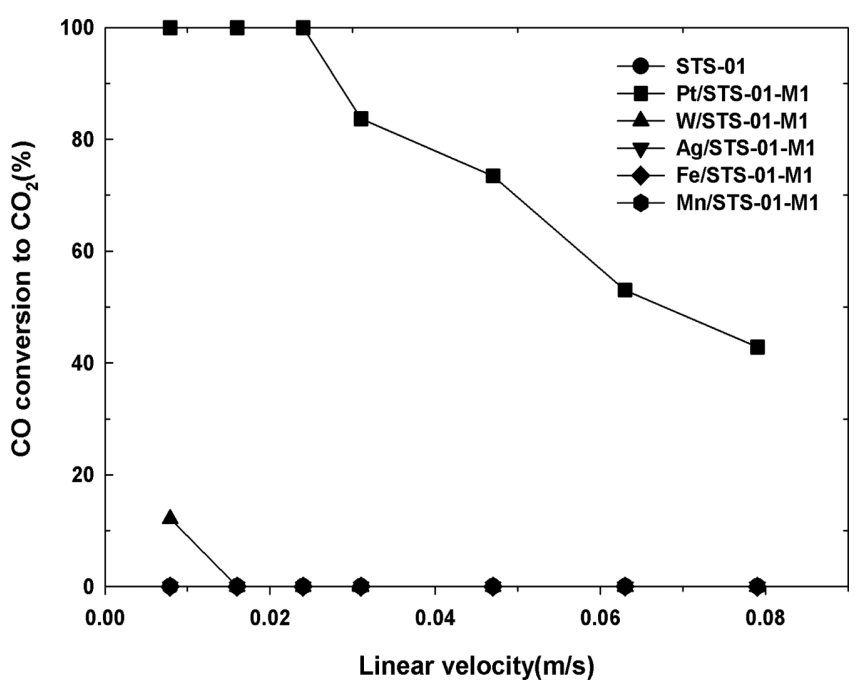

Fig. 4. $\mathrm{CO}$ conversion to $\mathrm{CO}_{2}$ according to support metal on STS-01 (moisture content : $40 \%$, Inlet concentration : CO $50 \mathrm{ppm}$ ).

$\mathrm{UV}$ 를 조사하여 각 금속을 담지하는 방법인 M1 방법을 사용하여 $\mathrm{Pt}, \mathrm{W}, \mathrm{Ag}, \mathrm{Fe}$ 및 $\mathrm{Mn}$ 의 여러 가지 금속을 담지하였다. Fig. 4에서 볼 수 있듯이 각 금속을 담지한 촉매를 사용한 반응관중 Pt/STS-01-M1의 반응관 만이 선속도 범위가 $0.01 \sim 0.025 \mathrm{~m} / \mathrm{s}$ 에서 $100 \%$ 의 $\mathrm{CO}$ 전환 율을 나타내었다. 그러나, 이 경우에도 반응관에 유입되는 $\mathrm{CO}$ 를 포 함한 기체흐름 선속도가 증가하면서 $\mathrm{CO}$ 를 전환하는 활성도는 점차 감소하는 경향을 나타내었다. 하지만 $\mathrm{Pt}$ 이외의 다른 금속을 담지한 경우에는 선속도에 상관없이 $\mathrm{CO}$ 제거 효율은 거의 나타나지 않았 다. 따라서 본 연구에서 고찰한 5 개의 금속중에서 $\mathrm{Pt}$ 가 가장 우수한 활성 금속임을 확인하였다. 


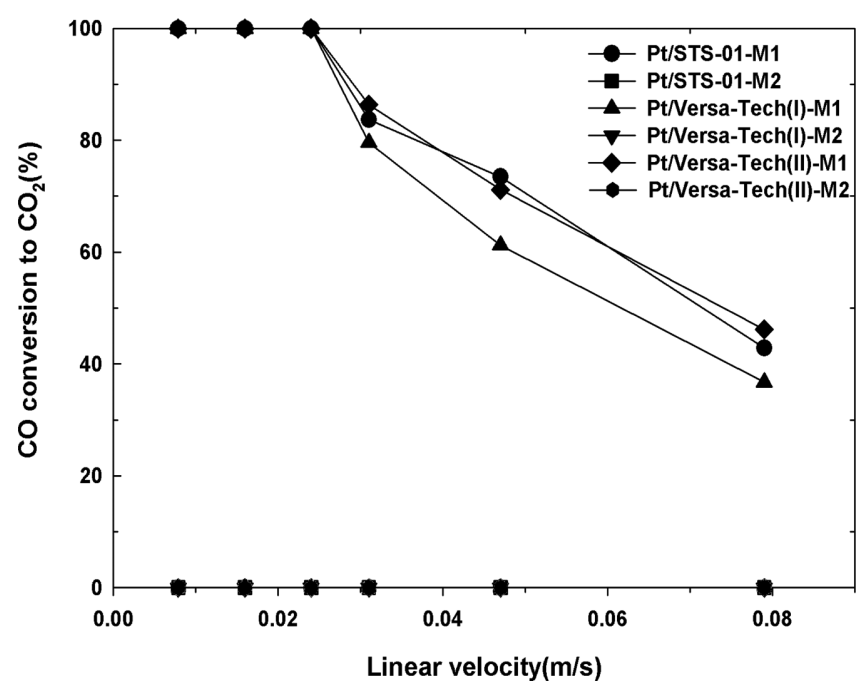

Fig. 5. CO conversion to $\mathrm{CO}_{2}$ according to support metal on $\mathrm{TiO}_{2}$ (moisture content : $40 \%$, Inlet concentration : CO $50 \mathrm{ppm})$.

세 가지의 $\mathrm{TiO}_{2}$ 에 $\mathrm{Pt}$ 를 동일량 담지하되 담지방법을 $\mathrm{M} 1$ 과 $\mathrm{M} 2$ 의 두 가지 방법으로 하여 각각의 경우에 광촉매 $\mathrm{CO}$ 산화반응 실험을 수행하여 그 결과를 Fig. 5에 나타내었다. Fig. 5에서 볼 수 있듯이 $\mathrm{M} 1$ 으로 제조한 $\mathrm{Pt}-\mathrm{TiO}_{2}$ 세 가지 촉매는 모두 선속도가 0.01 0.025 $\mathrm{m} / \mathrm{s}$ 에서는 $100 \%$ 의 전환율을 나타내었으며, 선속도가 증가할수록 모든 경우의 전환효율은 감소하는 것으로 나타났다. 하지만 UV Lamp를 조사하지 않고 binder와 혼합하기 전 증류수에 coating solution을 $\mathrm{TiO}_{2}$ 기준 $0.1 \%$ 양의 백금을 먼저 교반시킨 M2 방법으 로 제조한 촉매를 사용한 경우에는 기체흐름 선속도에 상관없이 세 가지 촉매 모두가 CO 전환활성을 나타내지 않았다. Kozlova[16] 등은 $\mathrm{Pt} / \mathrm{TiO}_{2}$ 제조 시 수은 $\mathrm{Lamp}$ 를 조사하였을 때 전자와 전공쌍은 $\mathrm{TiO}_{2}$ 표면에서 발생되며 광조사로 발생된 전자는 $\mathrm{Pt}^{4+}$ 를 $\mathrm{Pt}^{0}$ 으로 환원시 킨다고 보고하였다. 본 연구에서도 UV를 조사하여 제조한 촉매는 $\mathrm{TiO}_{2}$ 표면에 전자와 전공쌍이 발생되어 광촉매 반응시 발생하는 전 자가 표면의 $\mathrm{Pt}$ 를 쉽게 환원시켜 우수한 활성을 나타낸다고 설명할 수 있다.

$\mathrm{UV}$ 를 조사하여 관상반응관의 내벽에 코팅된 $\mathrm{TiO}_{2}$ 광촉매에 $\mathrm{Pt}$ 를 담지시킨 $\mathrm{Pt} / \mathrm{TiO}_{2}$ 의 세 가지 촉매에 대하여 각각 반응관에 유입되는 기체중에 포함된 $\mathrm{CO}$ 의 농도를 $20,50,100 \mathrm{ppm}$ 등 세 가지로 변화 시킨 경우에 $\mathrm{CO}$ 농도에 따른 광촉매 활성 변화를 Fig. 6에 나타내 었다. Fig. 6에서 볼 수 있듯이, $20 \mathrm{ppm}$ 의 $\mathrm{CO}$ 가 주입되었을 때 $\mathrm{Pt} /$ STS-01-M1 촉매의 경우 거의 $100 \%$ 의 우수한 CO 전환율을 나타 냈지만 $\mathrm{CO}$ 농도가 증가할수록 $\mathrm{CO}$ 의 전환율은 점점 감소하였으며, $\mathrm{CO}$ 가 $100 \mathrm{ppm}$ 의 농도로 주입될 때에는 Pt/STS-01과 Pt/Versa$\mathrm{Tech}(\mathrm{I})$ 촉매의 경우 $\mathrm{CO}$ 전환율이 $\mathrm{CO}$ 농도가 $20 \mathrm{ppm}$ 인 경우와 비 교하여 약 $20 \%$ 정도 급격히 감소하는 것으로 나타났다.

광촉매 반응공정에서 흐르는 기체의 의해 공급되는 수분함량(상 대습도)이 $\mathrm{CO}$ 의 반응전환율에 미치는 영향을 Fig. 7에 나타내었다. 수 분은 광촉매반응의 주요한 전자 수용체이며, 반응식(1)과 같은 전자 공여체가 되는 것으로 알려져 있다[17].

$$
\mathrm{h}^{+}+\mathrm{H}_{2} \mathrm{O} \rightarrow \mathrm{OH} \cdot+\mathrm{H}^{+}
$$

$\mathrm{TiO}_{2}$ 표면은 수분에 노출되었을 때 급격히 수산화되는데, 이는 수

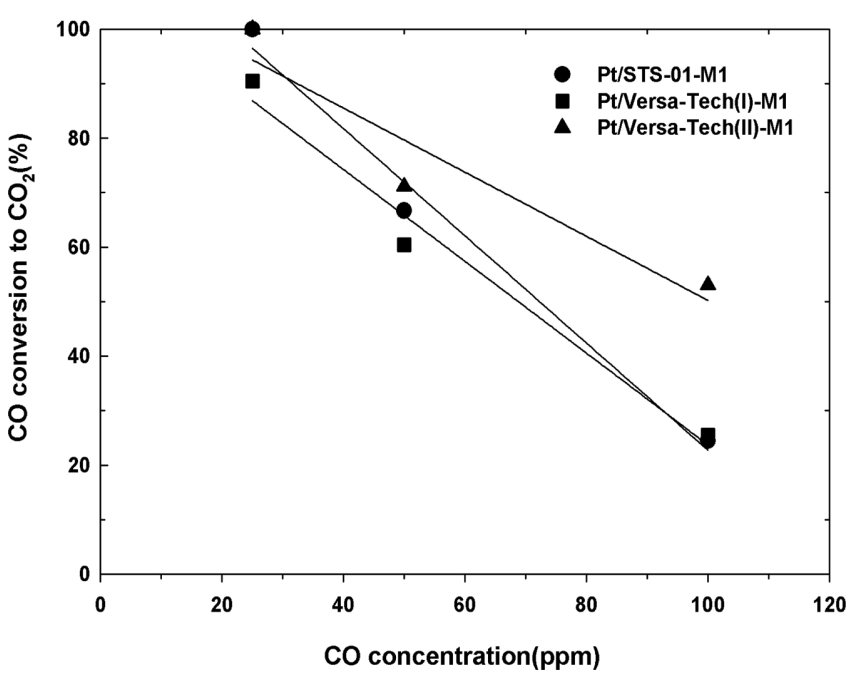

Fig. 6. $\mathrm{CO}$ conversion to $\mathrm{CO}_{2}$ according to inlet concentration (moisture content : $40 \%$, Linear velocity : $0.047 \mathrm{~m} / \mathrm{s}$ ).

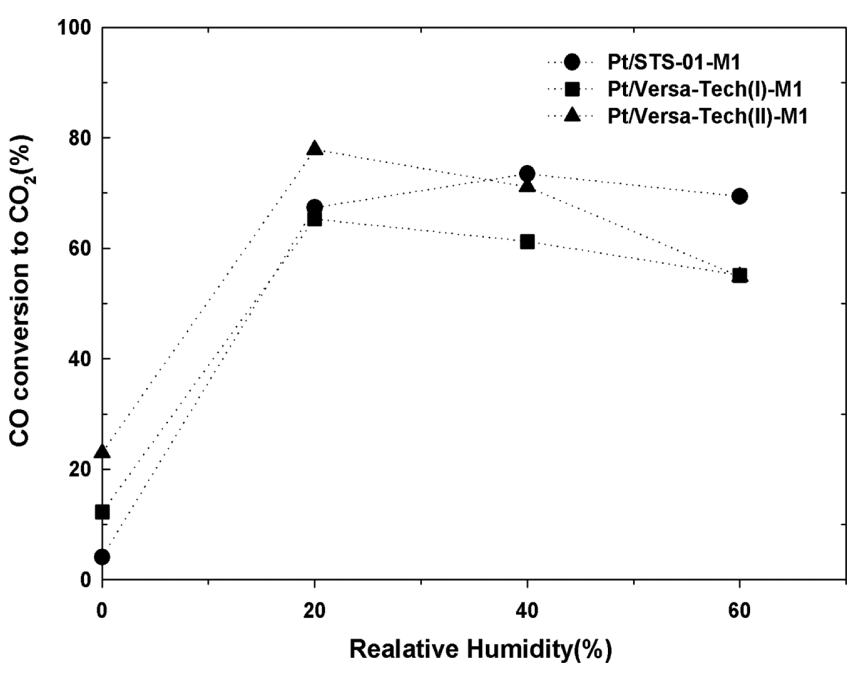

Fig. 7. The effect of promote metal on $\mathrm{H}_{2}$, CO slip over Pt catalysts. (a): CO slip, (b): $\mathrm{H}_{2}$ slip ( $\mathrm{NO} 728 \mathrm{ppm}, \mathrm{NO}_{2} 70 \mathrm{ppm}, \mathrm{O}_{2} 3 \%$, $\mathrm{CO}$ $100 \mathrm{ppm}, \mathrm{H}_{2} \mathrm{O} 8 \%$, S.V. $=30,000 \mathrm{~h}^{-1}$ ).

산화가 $\mathrm{Ti}^{4+}$ 부분과 물과의 화학흡착이 탈착되면서 일어나기 때문 이다. $\mathrm{TiO}_{2}$ 표면에 수분이 화학흡착되면 유기물은 그 위에 물리흡 착 되나, 수분은 수소결합에 의해 $\mathrm{TiO}_{2}$ 광촉매 표면의 수산화기와 물리흡착이 되기 때문에[17], 수분은 기체상태의 물질을 처리하고 자 할 때 중요한 변수가 되고 있다. 그러나, Fig. 7에서 볼 수 있듯 이 수분함량이 20 40\% 이상으로 높을 때 반응속도는 수분에 의해 방해를 받기 때문에[18-20], Pt/STS-01, Pt/Versa-Tech(I)와 Pt/Versa$\mathrm{Tech}(\mathrm{II})$ 의 세 가지 촉매 모두에 대하여 기체의 흐름 선속도가 0.047 $\mathrm{m} / \mathrm{s}$ 인 경우에 상대 습도가 $20 \sim 60 \%$ 범위에서는 $60 \sim 80 \%$ 의 CO 전 환율을 나타내면서 큰 활성의 차이를 보이지 않았다. 하지만 수분 이 없을 때는 세 촉매 모두 급격하게 효율이 감소함을 알 수 있었 다. 이러한 이유는 수분이 없을 때 $\mathrm{CO}$ 분해 과정에서 $\mathrm{OH}$ 라디칼이 생성되기 어렵기 때문에 $\mathrm{CO}$ 의 전환효율이 감소하는 것으로 사료되 었다. 


\section{4. 결 론}

$\mathrm{TiO}_{2}$ 광촉매에 $\mathrm{Pt}, \mathrm{W}, \mathrm{Ag}, \mathrm{Fe}$ 및 $\mathrm{Mn}$ 등 여러 가지 금속을 담지 한 후 관상반응기에 코팅하여 기체 흐름중에 포함된 $\mathrm{CO}$ 의 광산화 반응특성을 고찰한 결과 $\mathrm{Pt}$ 를 담지한 경우 만이 우수한 $\mathrm{CO}$ 가스의 제거효율을 나타내었다. 광촉매반응의 광원으로 UV 램프를 관상반 응기의 중앙에 수직으로 삽입한 $\mathrm{CO}$ 제거 공정에서 $\mathrm{Pt} / \mathrm{TiO}_{2}$ 광촉매 의 활성은 공정내부 기체흐름 선속도가 $0.01 \sim 0.025 \mathrm{~m} / \mathrm{s}$ 범위에서는 거의 $100 \%$ 의 CO 전환율을 나타내었으나 선속도가 증가할수록 CO 의 전환효율은 점점 감소하였다. $\mathrm{Pt}$ 를 $\mathrm{TiO}_{2}$ 에 담지하는 방법 중 $\mathrm{UV}$ 조사에 의해 $\mathrm{Pt}$ 를 관상반응기의 내벽에 코팅된 $\mathrm{TiO}_{2}$ 에 담지하는 방 법이 촉매의 광활성에 효과적인 것으로 나타났으며, $\mathrm{TiO}_{2}$ 촉매와 $\mathrm{Pt}$ 용액을 혼합 후 관상반응관에 코팅한 경우에는 $\mathrm{CO}$ 전환반응을 위 한 촉매의 광활성이 거의 나타나지 않았다.

$\mathrm{Pt} / \mathrm{TiO}_{2}$ 광촉매가 코팅된 $\mathrm{CO}$ 제거 반응관에서 흐르는 기체 중에 포함된 $\mathrm{CO}$ 의 농도가 증가할수록 $\mathrm{CO}$ 의 제거 효율은 감소하였으며, 본 $\mathrm{CO}$ 제거 공정은 배가스 중 $\mathrm{CO}$ 농도가 $100 \mathrm{ppm}$ 이하인 조건에서 적 용해야 효과적인 것으로 나타났다. $\mathrm{CO}$ 전환반응에서 기체에 포함 된 수분의 함량은 반응활성에 큰 영향을 미치지 않았지만, 수분이 존재하지 않을 경우 $\mathrm{OH}$ 라디칼을 생성하기 어려워 활성이 감소한 다고 사료되었다.

\section{참고문헌}

1. Poon, C. S. and Cheung, E., "NO Removal Dfficiency of Photocatalytic Paving Blocks Prepared with Recycled Materials,' Constr. Build. Mater, 21, 1746-1753(2007).

2. Kwon, T. R., Roo, W. H., Lee, C. W. and Lee, W. M., "Industrial Chemistry,Catalysis/Reaction Engineering : Preparation of Wall Paper Coated with Modified $\mathrm{TiO}_{2}$ and Their Photocatalytic Effects for Removal of NO in Air,' Korean Chem. Eng. Res.(HWAHAK KONGHAK), 43, 1-8(2005).

3. Dibble, L. A. and Raupp, G. B., "Fluidized-bed Photocatalytic Oxidation of Trichloroethylene in Contaminated Air Atreams," Environ, Sci. Tech., 26, 492-495(1992).

4. Hoffmann, A. J., Carraway, E. R. and Hofmann, M. R., "Photocatalytic Production of $\mathrm{H}_{2} \mathrm{O}_{2}$ and Organic Peroxides on Quantum-sized Semiconductor Colloids,' Environ. Sci. Tech., 28, 776785(1994).

5. Kormann, C., Bahnemann, D. W. and Hofman, M. R., "Photolysis of Chloroform and Other Organic Molecules in Aqueous Titanium Dioxide Suspensions,' Environ. Sci. Tech., 25, 494-500(1991).

6. Chen, D. and Ray, A. K., "Removal of Toxic Metal Ions from Wastewater by Semiconductor Photocatalysis,' Chem. Eng. Sci., 56, 1561-1570(2001).

7. Arai, T., Horiguchi, M., Yanagida, M., Gunji, T., Sugihara, H. and Sayama, K., "Complete Oxidation of Acetaldehyde and Toluene over a $\mathrm{Pd} / \mathrm{WO}_{3}$ Photocatalyst Under Fluorescent- or Visible-light Irradiation,' Chem. Commun., 43, 5565-5567(2008).

8. Yang, C. C., Yu, H., Linden, B., Wu, J. C. S. and Mul, G., "Artificial Photosynthesis over Crystalline $\mathrm{TiO}_{2}$-Based Catalysts: Fact or Fiction?,' J. Am. Chem. Soc., 132, 8398-8406(2010).

9. Carbajo, M., Enciso, E. and Torralvo, M. J., "Synthesis and Charcaterization of Macro-meso Porous Titania," Colloids Surf. A., 293, 72-79(2007).

10. Maira, A. J., Yeung, K. L., Lee, C. Y., Yue, P. L. and Chau, C. K., "Size Effects in Gas-phase Photo-oxidation of Trichloroethylene Using Nanometer-sized $\mathrm{TiO}_{2}$ Catalysts,' J. Catalysis, 192, 185-196(2000).

11. Ohno, T., Sarukawa, K., Tokieda, K. and Matsumura, M., "Morphology of a $\mathrm{TiO}_{2}$ Photo Catalyst(Degussa, P-25) Consisting of Anatase and Rutile Crystalline Phases,' J. Catalysis, 203, 82-86(2001).

12. Yang, J., Zhang, J., Zhu, L., Chen, S., Zhang, Y., Tang, Yi, Zhu, Y. and Li, Y., "Syntheses of Nano Titania Particles Embedded in Mesoporous SBA-15:Characterization and Photocatalytic Activity,' J. Hazardous Matr., B 137, 952-958(2006).

13. Kubo, W. and Tarsuma, T., "Photocatalytic Remote Oxidation With Various Photocatalysts and Enhancement of Its Activity,' J. Mater. Chem., 30, 3104-3108(2005).

14. Yang, J. H., Han, Y. S. and Choy, J. H., " $\mathrm{TiO}_{2}$ Thin-films on Polymer Substrates and Their Photocatalytic Activity,' Thin Solid Films, 495, 266-271(2006).

15. Zhan, S., Chen, D., Jiao, X. and Tao, C., "Long $\mathrm{TiO}_{2}$ Hollow Fibers with Mesoporous Walls : Sol-Gel Combined Electrospun Fabrication and Photocatalytic Properties,' J. Phys. Chem. B, 110, 1119911204(2006).

16. Kozlova, E. A., Lyubina, T. P., Nasalevich, M. A., Vorontsov, A. V., Miller, A. V., Kaichev, V. V. and Parmon, V. N., "Influence of the Method of Platinum Deposition on Activity and Stability of $\mathrm{Pt} / \mathrm{TiO}_{2}$ Photocatalysts in the Photocatalytic Oxidation of Dimethyl Methylphosphonate,' Catal. Commun., 12, 597-601(2011).

17. Obee, T. N. and Brown, R. T., " $\mathrm{TiO}_{2}$ Photocatalysis for Indoor Air Applications: Effects of Humidity and Trace Contaminant Levels on the Oxidation Rates of Formaldehyde, Toluene and 1,3Butadiene,' Environ, Sci. Tech., 29, 1223-1231(1995).

18. Ramaswamy, V., Awati, P. and Ramaswamy, A. V., "Epoxidation of Indene and Cyclooctene on Nano Crystalline Anatase Titania Catalyst,' Top. Catal., 38, 251-259(2006).

19. Chen, Y., Stathatos, E. and Dionysiou, D. D., "Microstructure Characterization and Photocatalytic Activity of Mesoporous $\mathrm{TiO}_{2}$ Films with Ultrafine Anatase Nanocrystallites,' Surf. Coat. Technol., 202, 1944-1950(2008).

20. Bosc, F., Ayral, A. and Guizard, C., "Mesoporous Anatase Coatings for Coupling Membrane Separation and Photocatalyzed Reactions," Membrane Sci., 265, 13-19(2005). 